\title{
Elementos de transnacionalidad en el comercio flamenco-holandés en Europa y la Monarquía hispánica
}

\author{
Ana CRespo Solana \\ Científica Titular del CSIC \\ Instituto de Historia \\ Centro de Ciencias Humanas y Sociales \\ Consejo Superior de Investigaciones Científicas \\ Albasanz 26-28 \\ 28037 Madrid, España \\ ana.crespo@cchs.csic.es
}

Fecha de recepción: 02/06/2011

Fecha de aceptación: 15/12/2011

\begin{abstract}
RESUMEN
Uno de los aspectos más estudiados sobre los mercaderes extranjeros en la España moderna fue su destacada función como actores y factores en el desarrollo del comercio exterior hispano. Sin embargo aún no se han descrito suficientemente cuáles fueron los mecanismos que condicionaron la inserción de estos comerciantes en la sociedad y la economía española teniendo en cuenta algunas importantes cuestiones relativas a su comportamiento como homo economicus. En esta presentación se hará un análisis histórico-sociológico de algunos elementos de cooperación y competencia que se desarrollaban en el seno de la comunidad neerlandesa (flamenca y holandesa) de Cádiz en el siglo XVIII en sus actividades comerciales y financieras. Estos agentes mercantiles, aparte de integrarse social y económicamente en Cádiz, gracias a sus vínculos familiares, desarrollaron unos mecanismos que explican tanto el considerable alcance de su red como el impacto de sus actividades económicas en un espacio socio-geográfico que se ampliaba más allá de las fronteras, conectando mercados atlánticos y globales.
\end{abstract}

Palabras clave: nación, redes mercantiles, comunidad mercantil, historia económica, historia social edad moderna, comercio internacional, transnacionalismo, siglo XVIII.

\section{Transnational Aspects of the Flemish-Dutch Trade in Europe and the Spanish World}

\begin{abstract}
One of the most well-known aspects of the foreign merchants in Early Modern Spain was their leading role as actors and factors in the development of the Spanish foreign trade. However, it has not been sufficiently described the mechanisms that determined the inclusion of these merchants in the Spanish economy and society by taking into account some important questions regarding their behavior as homo economicus. In this paper there will be a historical-sociological analysis of some elements of cooperation and competition that developed in the heart of the Flemish and Dutch communities in Cadiz during the Eighteenth Century, in relation to their commercial and financial activities. These commercial agents, in addition to their social and economic integration in Cadiz through family ties, developed certain mechanisms that explain both the considerable reach of the network as well as the impact of their economic activities in a socio-geographical space that extended beyond borders, connecting Atlantic and global markets.
\end{abstract}

Key words: Nation, Merchant Networks, Merchant Communities, Economic History, Social History, Early Modern World, International Trade, Transnationalism, Eighteenth Century. 


\section{EL COMERCIO DE LA MONARQUÍA Y EL COMERCIO EXTRANJERO}

La segunda mitad del siglo XVII fue la gran época del comercio extranjero en España. Esto no era algo nuevo ya que desde el siglo XV una gran parte del comercio exterior de la Corona de Castilla era conducido por intermediarios extranjeros. En una obra clásica y pionera dentro de la historiografía del comercio de Sevilla, Ruth Pike afirmaba que estos comerciantes (refiriéndose al caso de los genoveses): "jugaban un papel esencial en la financiación del comercio entre España y América (...), cuando el capital era escaso, los riesgos grandes y las tarifas de las mercancías muy costosas. Ellos daban dinero contante en forma de préstamos marítimos a personas que salían para el Nuevo Mundo, ayudándoles a armar sus barcos o a cubrir el coste de las mercancías". En más de un siglo la esencia de esta funcionalidad no se vio apenas alterada salvo por normas internas de la conducta social de los propios mercaderes cuando su inmigración a los reinos de la Monarquía hispánica se incrementó de forma considerable produciéndose un alto índice de simbiosis, más que integración en sí misma. Como los súbditos autóctonos del rey de España, también los mercaderes extranjeros llegaron a comprar sus títulos nobiliarios y sus asientos en los cabildos municipales, convirtiéndose así en ciudadanos honrados, de hecho y derecho ${ }^{2}$. Como siempre, los cambios en lo social también atendían a imperativos de la logística económica. El comercio exterior de la Monarquía hispánica se caracterizaba por constituir una próspera continuación estructural de unas relaciones que se bifurcaban entre las rutas del Báltico y el Mediterráneo mantenidas desde los centros económicos en torno a Amberes, Brujas, las ciudades hanseáticas y las italianas. Ello implicaba, pues, que este comercio pasaba obligatoriamente por Andalucía desde la Edad Media. Las instalaciones portuarias andaluzas que las casas de comercio habían organizado para llevar a cabo este importante comercio marítimo actuaron como factor de atracción a la continua llegada de nuevos inmigrantes (junto con la connivencia de otros tantos factores que se desencadenaron en el momento oportuno). Los orígenes de esta diáspora es algo que no se puede deslindar de la forma en cómo algunas de estas colonias de mercaderes extranjeros, como fue el caso de los neerlandeses, consolidaron sus "naciones" en la región andaluza y en la Monarquía hispánica en general ${ }^{3}$. Y ello no cambió nunca, en sentido estricto. El mercado regional del litoral andaluz de la edad moderna era un espacio integrado en la economía global de tal manera que su comercio alcanzó un volumen, diversidad y continuidad no igualado por otros enclaves mercantiles de la Península Ibérica. Además, canalizaba sus esfuerzos

\footnotetext{
PIKE, Ruth: Aristócratas y comerciantes. La sociedad sevillana en el siglo XVI, Barcelona, Ariel, 1978, pp. 107 y 108

2 Como ha sido también demostrado para el caso flamenco en la Sevilla del siglo XVIII. Cf. FERNÁNDEZ CHAVES, Fernando y Gamero Rojas, Mercedes: «Flamencos en la Sevilla del siglo XVIII, entre el norte de Europa y América», en Navarro Antolín, Fernando (coord.): Orbis incognitus: avisos y legajos del Nuevo Mundo: homenaje al profesor Luis Navarro García, 2 vols., Universidad de Huelva, 2007, pp. 211-220.

3 Esta situación estructural ha sido explicada por la historiografía en varias ocasiones. En el caso neerlandés, hay una síntesis en: Crespo Solana, Ana: Entre Cádiz y los Países Bajos. Una comunidad mercantil en la ciudad de la Ilustración, Cádiz, Fundación Municipal de Cultura, Cátedra Adolfo de Castro, 2001, pp. 43-103. Un ejemplo sintético sobre cómo afectaba a Andalucía el comercio europeo es: Pulido BuEno, Idelfonso: Almojarifazgos y comercio exterior en Andalucía durante la época mercantilista, 1526-1740, Huelva, 1993.
} 
a las empresas exteriores, viviendo prácticamente de espaldas al interior de España ${ }^{4}$. Esto era un factor que invitaba a participar en esta economía y también provocó, a partir de 1648, que las naciones mercantiles europeas compitieran entre ellas por ocupar una posición privilegiada en los negocios hispanos, especialmente en lo referente a la conexión americana. La crisis del comercio de las Provincias meridionales en la década de 1660 dio lugar a una preeminencia del transporte holandés hacia el sur, algo que poco a poco desbancó la rentabilidad y fiabilidad del convoy flamenco de Ostende ${ }^{5}$. El interés de las casas de negocios de Amsterdam por colaborar en el mantenimiento de estos enclaves mercantiles del sur peninsular aparece en muchas crónicas comerciales de la época y las obras de los analistas del período explican de forma ilustrada la funcionalidad de Cádiz en el comercio de intermediación con varios mercados ${ }^{6}$. Esto es algo que se ha podido constatar con el entrecruzamiento de documentos notariales que inciden en la importancia del ejercicio de la sucursalidad para comprender el papel económico, pero también social, de los agentes extranje$\operatorname{ros}^{7}$. Se trataba de una combinación entre la inversión de capital (monopolizado por Amsterdam) y la plaza subsidiaria de almacenamiento, dependencia muy clara dentro de una claramente diferenciada economía de escala que tenía mucho que ver, en el caso neerlandés, con las funcionalidades de los puertos-factorías a los que las flotas de las compañías y sociedades de los Países Bajos tenían acceso en todo el planeta. La creación en Amsterdam, en 1664, de un Collegie van Commercie en Kamer van Negotie (Colegio de Comercio y Cámara de Negocio), apoyado por los burgomaestres de Amsterdam, especificaba de forma clara la relación existente entre la fluidez de las inversiones dirigidas a los puertos-factorías y los viajes de comercio protagonizados por los agentes mercantiles ${ }^{8}$. Y esto era una razón de peso que en alguna ocasión se vio envuelta en un contexto de cooperación también en lo político militar, como cuando los Estados de la provincia de Holanda prestaron dinero a la Corona de la Monarquía hispánica para la organización del armamento marítimo del Estrecho de Gibraltar y el Mediterráneo9.

No obstante, en los estudios históricos actuales aún aparece como algo contradictorio y especialmente paradójico que las vivencias de los comerciantes extranjeros en España se hayan visto tan fuertemente condicionadas por los deseos de la Corona y el gobierno de la Monarquía en controlar, castigar, fiscalizar y, hasta cierto punto, hacer suyos, los productos y beneficios de sus actividades, surgiendo, empero, por

\footnotetext{
4 Ibidem, p. 211; Marcos Martín, Alberto: España en los siglos XVI, XVII y XVIII. Economía y Sociedad, Barcelona, Crítica, 2000, p. 14.

5 Fue un largo proceso político y económico que expliqué en: Crespo Solana, Ana: Mercaderes Atlánticos. Redes del comercio flamenco y holandés entre Europa y el Caribe, Universidad de Córdoba, Cajasur, 2009, pp. 56 y ss.

6 L'Espine, Le Moine de y Le Long, Isaac: De Koophandel van Amsterdam, naar alle gewesten der werelds. La edición citada aquí fue publicada en Rotterdam en 1753.

7 Crespo Solana, Ana: El comercio marítimo entre Amsterdam y Cádiz (1713-1778), Madrid, Banco de España, 2000, pp. 47-51.

8 L’Espine \& Le Long: op. cit. (nota 6), p. 779.

9 Archivo Histórico Nacional de Madrid (AHN), Estado (E), expediente 61: expediente del Condestable de Castilla y el enviado del Príncipe de Orange, 7 de julio de 1684. La suma total del préstamo alcanzaba los 80 mil florines y fueron otorgados por la Compañía de las Indias Orientales.
} 
otra parte, la imperante necesidad que la sociedad y la economía española en general tenía de aquellos mercaderes. Y es que en realidad las dos cosas no eran contradictorias. Los comerciantes inmigrantes constituían una de las primeras fuerzas de trabajo potencial de la expansión atlántica hispánica, al igual que lo fueron en otras zonas de Europa, pues este fenómeno de las diásporas mercantiles fue algo inherente a la propia dinámica del crecimiento económico europeo desde el siglo XVI y este éxodo fue el factor demográfico que más hizo crecer en número y prosperar a las poblaciones urbanas dedicadas a nuevas categorías socio-profesionales surgidas a partir del crecimiento económico registrado desde el siglo $X V^{10}$. Puede parecer también, quizás, extemporáneo que se pretenda analizar el significado que la presencia de la fuerza de trabajo extranjera (con todo lo que eso lleva de enriquecimiento cultural, económico y de implementación de nuevas dinámicas sociales) puede tener para el progreso de una colectividad, con los ojos del historiador del siglo XXI. Pero, para la historiografía modernista en general queda aún por explicar la paradoja de la diversidad y cómo queda este complejo proceso integrado en la sociedad del antiguo régimen. ¿Cómo se entiende la existencia de estas comunidades en la Europa moderna, su autoidentificación como "nación" dotada de características y atributos ciudadanos en un medio ambiente social compartimentado, caracterizado por la formación de derechos y exclusiones y, es más, su influencia decisiva en la expansión atlántica?

Este supuesto contrasentido entre deseo de control y necesidad de la connivencia de agentes tan dinámicos a la sociedad como fueron los mercaderes extranjeros dio lugar a que a lo largo de los siglos XVII y XVIII, y sobre todo después de las paces de Westphalia, se creara en los reinos de la Monarquía hispánica unos condicionamientos diplomáticos que ayudaron a crear una superestructura institucional que hiciese que algunas comunidades encontraran protección al amparo de las leyes de la propia composite Monarchy (fue el caso de franceses, genoveses, ingleses, flamencos y holandeses). Tanto los tratados diplomáticos, las juntas especiales, como posteriormente la Junta de Dependencias de negocios extranjeros, creada en 1714, pasaron de intentar un control exhaustivo con objeto de fiscalizar y castigar, a un estado de diálogo continuo con los representantes de las comunidades extranjeras a los que poco a poco otorgaron una situación jurídica de ciudadanos especiales acogidos a fueros y privilegios ${ }^{11}$. La Monarquía hispánica tuvo que claudicar ante los mercaderes extranjeros porque los necesitaba en una época en la que pasó también de ser una potencia hegemónica en guerra con todos a una nación que era sostenida económicamente

10 Esta línea, que en realidad es una visión innovadora sobre las comunidades mercantiles ha tenido importantes aportaciones recientes, fruto de auténticos trabajos en equipo, entre los cuales destacan: CrESPo SolANA, Ana (coord.): Comunidades transnacionales. Colonias de mercaderes extranjeros en el Mundo Atlántico (1500-1830), Madrid, Doce Calles, 2011; Subrahmanyam, Sanjay: Merchant networks in the early moderns world, Variorum, 1996; Vol. 8. An Expanding World: The European Impact on World History, 1450-1800; GeStrich, Andreas y SCHULte BEERBÜHL, Margrit (ed.): Cosmopolitan Networks in Commerce and Society, 1660-1914, London, German Historical Institute, 2011; Mukherjee, Rila (ed.): Networks in the First Global Age, 1400-1800, Delhi, Primus book, 2011; PARKER, Charles H.: Global interactions in the Early Modern Age, 1400-1800, Cambridge University Press, 2010; BöTTCHER, Nikolaus, Hausberger, Bernd e Ibarra, Antonio (coords.): Redes y negocios globales en el mundo ibérico, siglos XVI-XVIII, Iberoamericana, Vervuert, El Colegio de México, 2011.

11 Crespo Solana, Ana y Montojo Montojo, Vicente: «La Junta de Dependencias de Extranjeros (1714-1800): Trasfondo socio-político de una historia institucional», Hispania, vol. 69, n. 232 (2009), pp. 363-394. 
por las redes financieras transnacionales. Al amparo de este proceso, las redes de comercio consolidaron sus actividades en los territorios de la Monarquía hispánica y reforzaron la organización de sus rutas marítimas, a veces pugnando abiertamente y otras en abierta colaboración con sus vecinos y anteriores rivales. Esto fue de particular relevancia en las sociedades mercantiles asentadas en zonas urbanas marítimas de la Península Ibérica que se relacionaban con otras colonias en ciudades portuarias de otras partes de Europa, América y en buena parte del mundo no occidental, ya que el fenómeno puede definirse como global y, valga la redundancia, globalizante ${ }^{12}$. La economía exterior hispana estaba fuertemente condicionada por los imperativos del comercio con América y por el papel de intermediarios que llevaron a cabo estas colonias de mercaderes extranjeros durante generaciones. El comercio atlántico desarrollado por las flotas de Nueva España y el convoy de los galeones que vinculaba los puertos andaluces con los dos grandes virreinatos de Perú y Nueva España aglutinaba extensos negocios de re-exportación y largos circuitos de finanzas y almacenamientos procedentes de muchas áreas económicas. En realidad se trataba de una ruta global. Una buena parte de este comercio no lo hacían solo los extranjeros, como se ha demostrado ${ }^{13}$, pero los negociantes foráneos estaban implicados de forma determinante en las funciones de financiamiento y re-exportación de productos, por lo que las implicaciones con las economías locales fueron enormes ${ }^{14}$. Esto tiene una particular importancia visto desde las Antillas y los puertos continentales del Caribe donde el comercio vía Cádiz que hacían allí holandeses y flamencos alimentaba también la navegación que realizaba pequeños intercambios entre economías locales, como pasó en Puerto Rico o Cuba ya entrado el siglo XVIII, aunque esta participación viene de muy anterior ya que de forma también estructural los hacendados y mercaderes criollos necesitaban el capital extranjero para subsistir y esto se hacía en un extraordinario despliegue de cooperación mercantil en los márgenes del comercio no legalizado. Este comercio denominado clásicamente de contrabando en realidad era un comercio marginal entre áreas y agentes que no participaban de los monopolios establecidos pero que era muy importante dada la enorme dimensión económica que dio a estas regiones, que el propio sistema de flotas y galeones había marginado intencionadamente. En este sentido el comercio de contrabando directo también era incentivador del comercio intracaribeño al proveer, sobre todo, de productos para las colonias de plantación, en general ${ }^{15}$.

12 Picazo i Muntaner, Antoni: Colaboración y cooperación en la Primera Edad Global. Vol. II: El modelo hispánico: Redes y colaboración en las Filipinas, Londres, IdeaIndia, e-book, 2010; Crespo SolanA, Ana: «Geostrategy of a System? Merchant Societies and Exchange Networks as Connection Centres in the Spanish Atlantic Trade in the First Global Age», en MukHERJEe: op. cit. (nota 10), pp. 11-35.

13 Por ejemplo había unas importantes colonias de mercaderes autóctonos de dentro de la Península Ibérica, como los vascos o los catalanes: MARTínez del CERro GonzÁlez, Victoria: Una comunidad de comerciantes: navarros y vascos en Cádiz (Segunda mitad del siglo XVIII), Sevilla, Consejo Económico y Social, 2006.

14 La mayor parte de los estudios sobre comercio así lo demuestran, de tal manera que es imposible hablar de comercio en la España moderna sin hablar de los mercaderes extranjeros: cf. MARCos MARTín: op. cit. (nota 4), pp. 126-129. Esto es particular a nivel general, por ejemplo, en el caso de las colonias francesas: SALAS AusÉns, José Antonio: En Busca de El Dorado. Inmigración francesa en la España de la Edad Moderna, Bilbao, Servicio Editorial de la Universidad del País Vasco, 2010.

15 Se ha hablado mucho de esto pero apenas se ha enfocado desde el punto de vista de la cooperación entre agentes de todas las nacionalidades. CRESPO SOlANA, Ana: «¿Redes de dependencia inter-imperial? Aproximaciones teóricas a 
A pesar de todo, los estudios de historia económica que resaltan estas cuestiones casi no hacen hincapié en las relaciones sociológicas de base y apenas consideran la importancia de los cambios que acontecen en el comportamiento humano (considerando la historia económica como una auténtica behavioural science) a la hora de estudiar las funciones de los agentes mercantiles en la era pre-industrial ${ }^{16}$. El papel de los agentes mercantiles propició el crecimiento de los intercambios en zonas marginales en el área atlántica y consolidó la integración de los espacios económicos europeos. Para el caso del comercio andaluz que se llevaba a cabo en torno a los negocios de la Carrera de Indias, con sus elevados grados de interdependencia de esta mediación de agentes foráneos, se daba la circunstancia de una singular paradoja: allí en donde se había establecido aquel aparente sistema oficial centralizado por la Corona en un solo puerto, delimitado legalmente a los extranjeros y fiscalizado por unas instituciones de control, se constituyeron sociedades urbanas de base mercantil internacional que hacía que fuese, precisamente en estas ciudades (antes Sevilla y Cádiz desde 1717) en donde se rompía aquel mal llamado monopolio comercial ${ }^{17}$. $\mathrm{Y}$ es que la realidad estructural era muy concreta: el comercio exterior en general (incluyendo todas las áreas espaciales conectadas, desde el Báltico al ámbito americano) se articulaba en torno a un sistema self-organized constituido por redes de comunidades o sociedades mercantiles especializadas, núcleos complejos y flexibles que formaban redes evolutivas integradas en su marco correspondiente, e integrados por comerciantes, productores, y funcionarios gubernamentales. Eran, como se las ha definido: "redes comerciales flexibles de proyección internacional y basadas en relaciones de parentesco o de negocios" 18 .

La formación y consolidación de una amplia red de colonias asentadas en ciudades portuarias de la geografía de la expansión económica, estructuradas internamente de forma jerarquizada aunque con una determinada movilidad social, unidas por vínculos de parentesco y/o negocio, y organizadas localmente como una especie de corporaciones comunales en torno a vínculos de paisanaje, religión o, sobre todo, por compartir lengua e intereses comerciales comunes, fue un proceso que superaba los márgenes y fronteras de las complejas entidades estatales, nacionales o adminis-

la funcionalidad de los agentes de comercio en la expansión de las sociedades mercantiles», en PÉREZ TosTADO, Igor y García Hernán, Enrique (eds.): Irlanda y el Atlántico Ibérico. Movilidad, participación e intercambio cultural, Valencia, Albatros ediciones, 2010, pp. 35-50. Hay un ejemplo documental en donde se aprecia que las autoridades de la zona tenían constancia de esta consecuencia para la región: Archivo General de Indias (AGI), Santo Domingo, 492: autos de la presa del navío La América, en 1736.

16 Una reciente revisión sobre la historia económica en España en: CASAdo Alonso, Hilario: «The Economic History of Spain in the Early Modern Ages», en Ammannati, Francesco (a cura di): Dove va la Storia económica? Metodi e prospettive secc. XIII-XVIII / Where is economic History going? Methods and prospects from the XIIIth to the XVIIIth centuries, Firenze University Press, 2011, pp. 173-191.

17 Oliva Melgar, José María: El monopolio de Indias en el siglo XVII y la economía andaluza. La oportunidad que nunca existió, Universidad de Huelva, 2004, pp. 53-117. Hice hincapié en los mecanismos de esta particularidad que estaba alimentada especialmente por la corrupción de los funcionarios de la Casa de la Contratación en: CRESPO SolAnA, Ana: «Entente et concurrence: Les commerçants étrangers de Cadix après le transfert des institutions commerciales de Séville à Cadix en 1717», en Le Consulat de France à Cadix (1666-1740): Institutions, interêts et enjeux, Archives Nationales Paris, Journée d'étude, mars 2011.

18 Expliqué esta cuestión conceptual en: Crespo Solana: op. cit. (nota 15), pp. 35-50. Schulte-BeERbüHL, Margrite: «Merchant Empires: Mercaderes Hamburgueses en Londres y sus redes de comercio internacional (16601815)», en CRESPo Solana: op. cit. (nota 10), pp. 103-123. 
trativas existentes en la Europa del Antiguo Régimen. La comunidad mercantil de origen neerlandés en España era una auténtica red transnacional a pesar de lo quizás anacrónico del término utilizado para definir un proceso socio-cultural y económico que tuvo lugar en los siglos de la edad moderna ${ }^{19}$. Aquí transnacional se utiliza, en una primera acepción de tipo económico, para definir la cooperación entre negocios basados en más de una región, área o país, una perspectiva necesaria para el análisis de las interconexiones entre sociedades ${ }^{20}$. Ello también implica necesariamente un alto nivel de cooperación entre agentes. Es también paradójico que se trata de una fase de transición en la que tenían lugar formas de trabajo corporativo a niveles locales con la organización en red que demandaba la propia naturaleza de la producción y el intercambio global que se estaba implantando en las diferentes regiones interconectadas. La propia forma en la que estaba constituida la sociedad en la que estas comunidades se asentaban, con escasa tecnología para el trasvase de información, y en donde las distancias espacio-temporales constituían un reto difícil de superar para el individuo, los agentes sociales se esforzaron en generar nuevos vínculos de supervivencia colectiva basados en la confianza (tema muy analizado ya por los estudiosos) $)^{21}$ pero también en unos mecanismos tendentes a desarrollar ciertas formas de altruismo comunitario a niveles locales que los reforzaba a la hora de trascender sus vínculos de relaciones tanto con sus regiones de origen, con otras comunidades de su misma nación asentadas en otros lugares, como con otros ciudadanos de otras naciones en cualquier parte del mundo. Y esto es algo que puede apreciarse en el seno de la comunidad neerlandesa española.

Esto es relevante cuando se analiza conjuntamente la cuestión del trabajo en red transnacional y el desarrollo de un cierto sentido de identidad ciudadana que tanto caracterizaban a las "naciones" extranjeras de la edad moderna. Desde el punto de vista de las social networks mi intención es reconsiderar la importancia del estudio de los comportamientos en red de las sociedades mercantiles como núcleos generadores de determinados comportamientos humanos y la cuestión de la identidad ciudadana en el seno de estas comunidades corporativas, a nivel local. Precisamente, el sociólogo Garret Hardin definía en 1968 una particular tragedy of the commons haciendo referencia a la emergencia de nuevas formas de conductas o tácticas encaminadas al reparto y uso de los recursos que daba lugar a un fenotipo que generaba en un proceso conductual de los agentes sociales. Ello no era, sin embargo, un hándicap para la creación de ciertos mecanismos de integración hacia la búsqueda de un crecimiento global de las relaciones entre los seres humanos ${ }^{22}$. Aún lejos de la idea de que ello constituyese un rasgo biológico, propiamente dicho, en el estudio evolutivo de las

\footnotetext{
19 Crespo Solana: op. cit. (nota 10), "Introducción”, pp. 15 y ss.

20 Ibidem. Véase una síntesis teórica sobre Transnacionalismo e Historia Global en los siglos de la edad moderna en: Yun CaSAlilla, Bartolomé: «Localism, global History and Transnational History. A reflection from the historian of the Early Modern Europe», Historisk Tidskrift, n. 4/127 (2007), pp. 1-21.

${ }_{21}$ Por ejemplo, uno de los trabajos más recientes que han insistido en esto es: LAmikiz, Xavier: Trade and trust in the Eighteenth-Century Atlantic World. Spanish merchants and their overseas networks, Woodbridge, Suffolk, The Royal Historical Society/The Boydell Press, 2010.

22 Esta teoría ha tenido un gran impacto en la sociología y la biología evolutiva y ha revolucionado la perspectiva sobre la evolución del comportamiento humano a lo largo de la historia. Hardin, Garret: «The Tragedy of the Commons», Science, Vol. 162, n. 3859 (December 13, 1968), pp. 1243-1248.
} 
sociedades humanas tales atributos determinaban una forma de vida que implicaba fenómenos de cooperación dentro del dilema social. No es necesario resaltar que tales comportamientos eran más evidentes cuanto más abiertas, dinámicas y de fronteras eran estas sociedades mercantiles.

\section{COMUNIDAD Y COMPORTAMIENTO SOCIAL}

El comercio de Cádiz con América tenía una estructura oligopsónica. Precisamente una característica que ha sido menos valorada en lo referente a la funcionalidad de las redes de mercaderes, es que Cádiz y su bahía se había convertido en un mercado (primitivo) de derivados, un mercado secundario donde se negociaban opciones y futuros (generalmente derivados financieros y estrechamente relacionados con la especulación anticipada en los almacenajes de mercancías). Era un mercado subsidiario a su vez, de centros financieros del norte de Europa, como fue Amsterdam ${ }^{23}$. No es de extrañar así que el comercio flamenco de Cádiz volviese a remontar a partir de la década de 1720 gracias a su estrecha conexión en red con las actividades que se originaban en dicha ciudad portuaria, especialmente a través de las flotas de varias compañías de monopolio holandesas, sobre todo la de la Sociedad para el comercio de Levante de Amsterdam y Midelburgo que había acogido los negocios de muchos exilados políticos, religiosos y económicos de las ciudades del sur ${ }^{24}$. En este mapa de intermediarios especializados, la "ilustre y noble nación flamenca" actuaba "de facto" como habitáculo que acogía a muchos de esos agentes que operaban dentro de un mercado en el cual muy pocos comerciantes tenían mucho poder de mercado. Constituían una élite de compradores que tenían control en las decisiones sobre precios y sobre cantidades de productos disponibles para su venta. Actuaban como aglutinadores de beneficios y terminaban por ser los depositarios de un capital que servía para financiar nuevos negocios. En una tesis reciente se ha explicado cómo los mercaderes más ricos y poderosos eran los que monopolizaban un mercado negro de metales (coordinado por extranjeros, la mayor parte transeúntes que se dedicaban a comprar y vender para hacerse con el metal). La mayor parte de ellos estaban emparentados entre sí. Eran un oligopolio, y no un mercado competitivo. Estos mercaderes fijaban el precio del mercado en Cádiz, bajando el precio de la plata ${ }^{25}$.

Los mercaderes de origen neerlandés, junto con otros miembros de las colonias extranjeras, fueron auténticos protagonistas de este oligopsonio. Lo que aún se ha explicado menos es cómo la estructura de esta comunidad, fuertemente corporativa, proporcionaba los condicionamientos sociales, culturales e incluso religiosos para que este sistema comercial fuera tan competitivo pero a la vez tan colaborativo e integrado. Y es que las actividades económicas de estos agentes especializados de origen

23 Lesger, Clé: The Rise of the Amsterdam Market and Information Exchange: Merchants, Commercial Expansion and Change in the Spatial Economy of the Low Countries, c. 1550-1630, Burlington (VT), Ashgate, 2006.

24 Algo que ya expliqué extensamente en: Crespo SolanA: op. cit. (nota 7), pp. 32 y ss.

25 Nogués-Marco, Pilar: Did Bullionism matter? Evidence from Cadiz shadow market for Silver, 1729-1741, Primer Encuentro Anual de la AEHE, Barcelona, septiembre, 2009. 
extranjero estaban en realidad muy conectadas cultural y espacialmente con su organización interna comunitaria como micro-sociedad que a su vez le otorgaba la suficiente capacidad y fortaleza para soportar amplios negocios en red. En este sentido sabemos los historiadores que la visualización de estas complejas social networks de mercaderes es el new challenge de la investigación social y económica del futuro con el objeto de apreciar las auténticas dimensiones de estos mecanismos de integración espacial. Por el momento es tarea difícil recomponer el rompecabezas de la información documental y en este sentido se pueden establecer dos análisis complementarios que se defienden en este artículo: por una parte, estudiar la evolución del compromiso de los mercaderes extranjeros con lo institucional y sus implicaciones en la configuración interna de la comunidad y su identidad de "nación"; y por otra, la capacidad de esta comunidad corporativa y local para su despliegue en red transnacional.

Siempre afirmé que en el campo de estudio de las comunidades mercantiles, la colonia formada por flamencos y holandeses en el Cádiz de los siglos XVII y XVIII aparece como un ejemplo paradójico y modélico de lo que era una "nación" mercantil de origen extranjero en la Europa del Antiguo Régimen ${ }^{26}$. Eran, en sentido estricto, una colonia corporativa que defendía los bienes comunales de la comunidad, la reputación de los miembros con más riqueza y tenían un concepto de ciudadanía basada en los fueros de grupo, leales, católicos y dedicados al comercio. En sus memoriales a la Junta de Dependencias de Extranjeros defendían precisamente ese doble cariz de leales y fieles servidores, a través del comercio, a Su Majestad ${ }^{27}$. Como mercaderes, en relación a sus colaboraciones con los holandeses y, a veces, en su tramoya con los propios españoles u otros nacionales de otras "naciones", destacó siempre el hecho que ellos mismos "no pretendían estar sin sujeción sino subordinados a un juez de integridad, rectitud y justificación", y que reivindicaban tener la necesidad de esa "forma de matrículas que han observado para que conste los verdaderos individuos y que de ninguna forma se les precise a separarse del apetecido vasallaje que obtienen", pues, como miembros de esta corporación local que fue la antigua y noble nación flamenca ${ }^{28}$. Sus bienes comunales estaban administrados por un mayordomo de la nación elegido entre los miembros más destacados de la comunidad, en un patronato que incluía la propiedad de una serie de inmuebles en Andalucía, sobre todo en las provincias de Cádiz y Sevilla, y el enterramiento colectivo adscrito a la cofradía de San Andrés de los flamencos en la iglesia conventual de San Francisco de la citada ciudad $^{29}$. En sus memoriales elevados a la Junta de Dependencias de Extranjeros de-

26 CRESPO SolanA, Ana: «Flandes y la expansión mercantil europea: origen y naturaleza de una red atlántica (siglos XV-XIX)», en Paz, Manuel de (dir.): Flandes y Canarias. Nuestros orígenes nórdicos (III), Tenerife, Taller de Historia, 2007, pp. 13-81.

27 AHN, E, 623, expediente 532.

28 Ibidem. El nombre de "Antigua y noble nación flamenca y alemana de Sevilla y Cádiz" aparece en toda la documentación de los flamencos y también en los memoriales y en las correspondencias de muchos mercaderes de los Países Bajos septentrionales, e incluso de amplias zonas de Alemania, debido a que el origen de esta colonia se enmarca en una época en la que estos territorios no estaban muy delimitados en sus fronteras y eran casi todos feudos de príncipes del imperio o del propio emperador, como bien recogía Luis Guichardino en su "Descripción de (....) de todos los Países Bajos que por otro nombre se llaman la Alemania la Baja, al Gran Rey Católico. Descripción General de los Estados de Flandes", Biblioteca Nacional de Madrid, Manuscrito 786.

29 El patronato y su cofradía están detalladamente explicados en: CRESPO SolANA, Ana: «El patronato de la nación 
finen ellos mismos este concepto de ciudadanía corporativa local cuando defendían la integración de la comunidad y el mantenimiento de este patronato con sus bienes que les servían para poder llevar a cabo obras de acogida para otros mercaderes transeúntes así como diversas obras pías a nivel social ${ }^{30}$. Además, la reputación de ser buenos comerciantes acogidos a un fuero especial y la garantía de ser generosos y piadosos con el resto de los componentes de la comunidad, y de la sociedad en general, demostraba su capacidad para el bien común. En teoría, era esto y no otra cosa lo que les hacía merecedores de su fuero y del juez conservador de su "nación":

[...] Sobre cuya instancia [...] le constaba ser cierto todo lo que referían en cuanto a las obras pías, como también que con la separación de algunos iban decayendo los efectos en que podía consistir su subsistencia, si bien no podía asegurar si esto había sido por causa de hallarse sin la exención que antes tenían, pero que en su concepto no tenía duda que si se les concediese el Juez conservador en la forma que se proponía, volverían los pocos que se habían separado, el gremio de la misma hermandad y cesaría el recelo de que decreciese o se perdiese con el tiempo el culto de la capilla y los santos fines de su instituto ${ }^{31}$.

No es necesario entonces repetir que esta "nación flamenca" española se consolidó tras un largo exilio político, religioso y económico consecuencia de una gran diáspora entre 1560 y 1648. Después de dicho año esta comunidad se encontraba con la irreversible singularidad de proceder de una región dividida jurídicamente: la República Holandesa y los Países Bajos meridionales que continuaban dentro de la órbita política de la Casa de Habsburgo. Esto, sin duda, repercutió en la formación de una identidad diferencial (de tipo político y religioso) que en la práctica apenas tuvo relevancia, sobre todo en lo referente a cuestiones económicas y de intereses comerciales. En varios informes elaborados a partir de 1687 los flamencos exigían que se les permitiesen los mismos privilegios, exenciones comerciales y franquezas que tenían franceses, ingleses, holandeses y hanseáticos con los que comerciaban en una u otra proporción. Pedían que en lo referente a las visitas de sus navíos, lonjas, libros y almacenes se les observasen las mismas reglas y se oponían a ser incluidos en las represalias que, con motivo de la guerra de Sucesión, se dictaron contra holandeses e ingleses ${ }^{32}$, y afirmaban que "desde el tiempo de la antigua fidelidad de Flandes se les distinguió de las provincias rebeldes" ${ }^{33}$. Pero en la vivencia del día a día local, por cuestiones lingüísticas, a veces también religiosas, pero sobre todo por imperativos de lo que se podría denominar como de logística económica espacial, los neerlandeses que residían en las ciudades de la Monarquía hispánica estaban muy conectados entre sí. En la documentación notarial la mayor parte de los emigrantes procedentes

\footnotetext{
flamenca gaditana en los siglos XVII y XVIII: trasfondo social y económico de una institución piadosa», Studia Historica, Historia Moderna, vol. 24 (2002), pp. 297-329. Vid. ut supra.

30 AHN, E, 623 (2), expediente 532: informe a la Junta de Dependencias de Extranjeros, 18 de agosto de 1722.

31 AHN, E, 623 (2), expediente 532: informe del regente de Sevilla, Don Manuel de la Torre, sobre la nación flamenca.

32 Ibidem. Se trata de la represalia dada por Real Cédula de 9 de noviembre de 1702

33 Ibidem.
} 
de la República Holandesa aún afirmaban ser "flamencos" cuando se encontraban de paso por España o dispuestos a residir en las ciudades comerciales de la Monarquía ${ }^{34}$. Los privilegios de los flamencos en España, otorgados desde tiempos del emperador Carlos I, les daba una especial categoría de ciudadanía española que los propios miembros de la nación flamenca se preocuparon de reivindicar hasta el final, incluso cuando después de 1713, la Monarquía hispánica perdió los Países Bajos del Sur ${ }^{35}$.

El estudio de la evolución de dichos privilegios es difícil y ya los he resumido en anteriores publicaciones por lo que se procederá a una síntesis muy breve completada con la información localizada recientemente ${ }^{36}$. La "Ilustre nación flamenca de Sevilla y Cádiz" tenía depositados diversos documentos de naturaleza jurídica en los archivos de las iglesias donde tenían constituidas sus cofradías y mayordomías de la comunidad pero muchos de estos papeles parecen haber desaparecido, como fue en el caso de las iglesias del Rosario y de San Francisco de Cádiz, o en el caso de la iglesia de la Encarnación de Sevilla ${ }^{37}$. Algunos indicios importantes revelan la existencia de estos privilegios que en principio tuvieron un cariz meramente comercial para los mercaderes en tránsito (como las "cartas de marca", estudiadas por Raymond Fage ${ }^{38}$ ), o proporcionaba a ciertos individuos un estatuto de vecindad. En términos generales, se pueden distinguir dos tipos de privilegios: los propios que adquirieron como extranjeros acogidos a un fuero español por haber sido súbditos del rey de España (no olvidemos que los flamencos esgrimieron este tema hasta el final) y los que lograron como extranjeros vecinos y más tarde sus hijos, los jenízaros, en el contexto de las actividades del comercio colonial ${ }^{39}$.

En relación a lo primero, el rey de España pactó una serie de privilegios con las autoridades del gobierno de Bruselas, en tiempos de los Archiduques que posteriormente fueron confirmadas por el gobierno del Imperio, pero de los cuales sólo existen también algunos indicios indirectos, como la alusión a una Pragmática de 1533, hallada en un documento de hidalguía de un comerciante holandés de Cádiz, que hace alusión a unos favores especiales otorgados a las comunidades en España por Carlos $\mathrm{V}$, y más tarde refrendada por los Archiduques ${ }^{40}$. Con la creación de la cofradía de San Andrés, la nación flamenca vio confirmados estos privilegios cuando Felipe IV fijó los estatutos a favor de la referida nación y su confraternidad en todos sus reinos ${ }^{41}$. Durante el siglo XVII la nación flamenco-española negoció la obtención de "fueros de conservaduría", al igual que lo tenían otras naciones. Estos fueros fueron también

\footnotetext{
34 Era algo que aparece muy a menudo en los poderes para testar y en los testamentos, que la mayor parte afirma ser "natural de Flandes". CRespo Solana: op. cit. (nota 3), p. 133.

35 AHN, E, 623, expediente 532 (passim).

36 Véase mi artículo: Crespo Solana: op. cit. (nota 26), pp. 13-81.

37 Hye Hoys, I.: Fondations pieuses et charitables des marchands flamands en Espagne, Bruselas, Précis Historiques, 1882, n. 31.

38 FAGEL, Raymond: De Hispano-Vlaamse wereld. De contacten tussene Spanjaarden en Nederlanders, 14961555, Bruselas, Nimega, 1996, p. 224.

39 García-Mauriño Mundi, Margarita: La pugna entre el Consulado de Cádiz y los jenízaros por las exportaciones a Indias (1720-1765), Sevilla, 1999, pp. 30-69.

40 Como en el documento de hidalguía de un comerciante de origen holandés, Diego de Roy. Archivo Histórico Municipal de Cádiz (AHMC), Libro 10.601/4.4.

41 AHN, E, 641.
} 
confirmados en 1738 y aceptados por los cónsules de las naciones francesas (en ese momento Juan Partyet), la británica (Guillermo Geyley) y holandesa (Leonardo Van Halst) con objeto de consensuar el derecho de las naciones a que solo los jueces conservadores pudieran conocer acerca de sus causas civiles y criminales internas en la comunidad. Era un "privilegio de Fuero" para todos los individuos acogidos a una comunidad que hasta cierto punto parece un contrapunto a la necesidad de ennoblecerse para obtener honor y protección dentro de la sociedad ${ }^{42}$. Llama la atención que los flamencos se unieron a ingleses y holandeses, al menos en lo referente a derechos relacionados con las actividades del comercio y su función como consignatarios en el puerto, ya que reclamaban también estar incluidos en los acuerdos firmados el 24 de junio de 1687, 9 de marzo de 1688 y 21 de agosto de 1692, sobre diversos privilegios relacionados con sus almacenes, sus actividades en las lonjas y su papel como consignatarios de comercios. Por una Real Cédula del 6 de abril de 1705 se extendió estos privilegios "a que la excepción y seguridad de sus géneros se entendiese aún en el caso de transportarse a Cádiz (las mercancías) en navíos de otras naciones"43. Las "naciones" tenían facultad para nombrar al juez conservador pero no podían confirmarlos con precisión, permitiéndose en la práctica a los gobernadores militares conocer los contenidos de las causas ${ }^{44}$.

Respecto al segundo tipo de privilegio, relacionado con su capacidad para comerciar con América, destacaban las "cartas de naturaleza", que era una forma de ser considerado súbdito del rey de España, tras un proceso durante el cual los interesados debían demostrar una serie de cumplimientos con las leyes de la Corona ${ }^{45}$. John Everaert contabilizó unas 314 naturalizaciones de flamencos entre 1598 y $1700^{46}$. En muchos documentos relativos a las naturalezas de los flamencos hay algunos problemas relacionados con el uso del término "Flandes", ya que en algunas ocasiones se otorgó carta de naturaleza a mercaderes nacidos en la República Holandesa pero que se declaraban ellos mismos originarios "de las tierras de Flandes" ${ }^{47}$. En estos casos, profesar el catolicismo era casi una marca de identidad flamenca independientemente de la ciudad de nacimiento del aspirante a naturalizado español ${ }^{48}$. Pero la cuestión más trascendental referente a esta identidad flamenco-española se ve reflejada en los memoriales elevados a la Junta de Dependencias de Extranjeros en la década de 1720. De estas representaciones es fácil derivar que la "Antigua y noble nación flamenca"

42 Nationaal Archief, La Haya, (NA), Archivo Levantse Handel, 173, Carta del gobernador de Cádiz sobre los fueros de las naciones (año 1738). No consta la fecha de la confirmación de estos privilegios.

43 AHN, E, 641, expediente 716: informe del 17 de noviembre de 1727 sobre los privilegios de la nación flamenca.

44 NA, Archivo Levantse Handel, 173.

45 Estas cuestiones han sido muy explicadas. Cf. una síntesis de lo que esto suponía para los mercaderes extranjeros en: Herzog, Tamar: Vecinos y extranjeros: hacerse español en la edad moderna, Madrid, Alianza, 2006, pp. $145-177$.

${ }^{46}$ Everaert, J.: «Infraction au monopole? Cargadores-navegantes flamands sur la Carrera de Indias (XVIIe siècle)», en Acosta Rodríguez, Antonio, González Rodríguez, Adolfo y Vila Vilar, Enriqueta (coords.): La Casa de la Contratación y la navegación entre España y las Indias, Universidad de Sevilla, CSIC-EEHA, Fundación El Monte, 2003, pp. 761-777.

${ }_{47}$ Como fue el caso del capitán Juan de Banes en 1693: AGI, Contratación, 51B: ejecutoria de 22 de junio de 1693.

48 Otros documentos de cartas de naturalezas de flamencos y holandeses: AGI, Contratación, 50B: naturalizaciones de flamencos (1584-1672); Contratación, 596B (1612-1693) (1698) y Contratación, 5470. 
española era una institución con un fuero propio, privilegiados por leyes y disposiciones, que tenía su archivo particular, sus propios jueces y una jerarquización dentro de la propia colonia con un mayordomo electo que actuaba como un representante legal de la comunidad ante los poderes fácticos, incluyendo la Corona ${ }^{49}$. Es aquí donde se entra de lleno a aclarar lo que suponía la auto-identificación con esta "nacionalidad flamenco-española" en el contexto social y económico del mercader flamenco u holandés que se incluía dentro de la nación flamenca, como católico (al menos oficialmente) y como súbdito del rey de España. Esto último fue un problema enorme para la nación flamenca después de Utrecht, porque el traspaso de la soberanía de las Provincias meridionales de los Países Bajos al Imperio implicó que, efectivamente, ya no eran súbditos del rey de España cuando ellos continuaban luchando por la defensa de unos privilegios que se habían ganado por su lealtad en siglos precedentes. Así que esta cuestión política parece amenazar y romper a la nación flamenca precisamente cuando gozaban de unos extraordinarios beneficios con su comercio con América y en su papel de intermediarios y consignatarios de sus socios del norte de Europa, en especial, del comercio que se distribuía a través del mercado de Amsterdam. Esto fue realmente un problema durante el desacuerdo interno en la nación en relación a la elección del cónsul, como bien ha demostrado Manuel Bustos Rodríguez ${ }^{50}$.

Para contrarrestar esto, los mercaderes neerlandeses exhibieron una ejemplar cohesión interna de ciudadanía y cooperación, y ello fue posible gracias a la propia estructura corporativa de su comunidad. En la historia, la cuestión de la ciudadanía ha constituido una ambigua institución que ha sido compatible con muchas formas de poder político y de relaciones sociales intrínsecas. Ha significado derecho y exclusión, por lo que también ha sido un principio de discriminación y ha asentado el derecho a los privilegios de ciertos grupos sociales ${ }^{51}$. Y es que tanto a nivel de sociedad como de estado, los individuos han tenido siempre necesidad de dinero, poder, lealtad, cooperación, etc. en una variedad de formas; los individuos han necesitado seguridad, justicia, liderazgo, comida y, a menudo, protección comercial. Los miembros de las comunidades tenían la capacidad de gobernar internamente dentro de la comunidad gracias a una serie de valores morales que valorizaban el bien común pero que a la vez potenciaba la cooperación y el altruismo social en forma de la confianza en los negocios o en la creación de instituciones piadosas y de socorro espiritual y material, como fue el caso de la Cofradía de San Andrés de los Flamencos, que también gestionaba la nación flamenca ${ }^{52}$. La ciudadanía dentro de una comunidad mercantil o "nación" estaba relacionada con la idea de auto-gobierno y era de pequeña escala, culturalmente monolítica, jerárquica y discriminatoria (en un aspecto que hoy se podría denominar como de discriminación positiva), moralista, idealista, espiritual, activa, participativa, comunitaria, y también heróica, pues demandaba la

49 AHN, E, 641, expediente 716.

50 Bustos Rodríguez, Manuel: «Les Consulat des Flamands à Cadix après la Paix d’Utrecht (1713-1730): Jacques Vermolen», en Parmentier, J. y Spanogue, S: Orbis in Orbem. Liber Amicorum John Everaert, Gante, 2001, pp. 109-133.

51 Riesenberg, Peter: Plato to Rousseau. Citizenship in the Western Tradition, The University of North Carolina Press, 1992, Introduction, pp. 17 y ss.

52 Crespo Solana: op. cit. (nota 29), pp. 297-329. 
implicación de los componentes de una comunidad acogidos a los "fueros". Se podía definir como "orgánica", es decir, tal como eran las propias comunidades de mercaderes extranjeros (quizás en general) dentro de una sociedad de antiguo régimen.

En el seno de esta comunidad orgánica que era la nación, los lazos familiares, el padrinazgo por razones religioso-familiares y las redes de confianza basadas en la reputación desempeñaron un importante papel a la hora de mantener los negocios de comisión e intermediación a través de diversas redes. La familia y los negocios otorgaron a los negociantes arraigados la posibilidad de formar un grupo compacto y definido socialmente por los privilegios y características de su nación. Por otra parte, los intereses de las redes de corresponsales y el establecimiento de los negocios mercantiles de acuerdo a compañías, con todas sus ramas de negociantes subsidiarios, y el establecimiento de los Consulados, fue, en la práctica, suficiente aliciente para la atracción de inmigrantes. La comunidad constituía, pues, una microsociedad de familiares y amigos dispuestos a ser receptáculo para el recién llegado, razón del notable incremento de la migración transeúnte formada principalmente por viajeros y aprendices de comercio, muchos de los cuales tenían contratos verbales o escritos que definían los servicios que como intermediarios llevaban a cabo para las compañías de comercio ${ }^{53}$.

Relacionado con esta integración ciudadana estaban las propias actividades económicas en sí mismas. En realidad, y desde el punto de vista de la cooperación en sociedad, la elevada migración llegada durante generaciones a estas ciudades había derivado en la creación de un social environment de frontera, muy dinámico, caracterizado tanto por el contrabando como por el comercio legal, vistos como dos tipos de actividades complementarias en respuesta a las versátiles oportunidades económicas generadas en este tipo de sociedad. Pero también, como he apuntado en un artículo reciente, esta dinámica sociedad, y la estructura del mercado generado, hizo emerger nuevos procesos de colaboración y competencia que empujaron a los agentes comerciales, tanto extranjeros como autóctonos, a desarrollar distintos mecanismos de simbiosis y cooperación dentro del propio sistema comercial español. Esta actividad económica así como los propios mecanismos de cooperación se centraban pues en la intermediación en el control de los precios, mediante la intervención a su vez de la entrada de metales, y en el tamaño del mercado ${ }^{54}$. En este mercado tenía lugar tanto el contrabando como el despliegue de una serie de estrategias legales (no contrabando en sí) que operaba en simbiosis con las propias y a veces, ambiguas o no muy claras normativas del supuesto monopolio de estado. El contrabando daba lugar, no solo a beneficios económicos que sin duda los tendría (aunque difíciles de constatar) sino también a beneficios sociales no monetarios que se reflejan en la participación de los agentes en el reparto de prebendas sociales ${ }^{55}$.

53 Crespo Solana: op. cit. (nota 7), p. 45.

54 Crespo Solana, Ana: «Legal Strategies and Smuggling mechanisms in the foreign merchant's trade in Cadiz with the Hispanic Caribbean. The Dutch and Flemish Case (1680-1750)», Jahrbuch für Geschichte Lateinamerikas, 47 (2010), pp. 181-212.

55 PIJNING, Ernst: «A New Interpretation of Contraband Trade», Hispanic American Historical Review, 81: 3-4 (2001), pp. 733-738. 


\section{COOPERACIÓN ECONÓMICA ENTRE FLAMENCOS Y HOLANDESES EN LA CARRERA DE INDIAS}

Cádiz fue la ciudad donde la comunidad neerlandesa formada por ciudadanos procedentes del norte y el sur de los Países Bajos fue más numerosa, al menos que se haya demostrado cuantitativamente hasta el momento ${ }^{56}$. Es cierto que quedan pendientes de estudio algunas ciudades pero hasta que algún bienintencionado análisis no logre desbancar esta hipótesis, primero Sevilla pero sobre todo Cádiz, a partir de la década de 1620 , fueron las ciudades de la nación flamenca por antonomasia ${ }^{57}$. Los escasos documentos que han resistido al tiempo, del archivo de la nación, y que se encontraban depositados en la Iglesia del Rosario de Cádiz (actualmente en el Archivo Diocesano de la ciudad principalmente) $)^{58}$ afirmaban que su establecimiento en la ciudad era muy antiguo. En un memorial elevado en 1727 a la Junta de Dependencias de Extranjeros se afirmaba que:

se ignora la antigua residencia y habitación en aquella ciudad de la nación flamenca y solo consta que fue anterior al año de 1598 en que el cuerpo de ella se hallaba con casas propias y gobernada por un mayordomo que anualmente había sido nombrado para atender los negocios comunes con cuyo régimen se conservaban hoy habiendo logrado en la duración de dos siglos entre repetidas honras de V.M y de sus gloriosos predecesores la más especial en duplicados vínculos de vasallaje en el origen de su nación que conservaban habitando allí y en muchos pueblos de su contorno con sus familias y haciendas, raíces, contribuyendo a proporción a cuanto se ha ofrecido del real servicio como verdaderos patricios y fieles vasallos abandonando los intereses de su patria y las herencias y conveniencias diferidas por natural derecho ${ }^{59}$.

Para el caso de Cádiz, las primeras décadas del siglo XVIII habían supuesto un colofón para un proceso económico e institucional que se había iniciado realmente en la segunda mitad del siglo XVII. En este proceso de cambio intervinieron varios factores que convirtieron a toda el área de la bahía de Cádiz en un espacio geográfico preferente para las inversiones de capital extranjero destinado sobre todo al comercio colonial, aunque hubo algunas excepciones ${ }^{60}$. La historiografía más tradicional se resiste a cambiar su idea sobre el "problema de los extranjeros" como artífices de la

\footnotetext{
56 En realidad no se han cuantificado estrictamente en todas las ciudades donde residieron, aunque Eddy Stols elaboró un valioso apéndice con una lista de 587 mercaderes para la Sevilla del siglo XVI y quizás fueron más de los que están. Stols, Eddy: De Spaanse Brabanders of de handelsbetrekkingen der Zuidelijke Nederlanden met de Iberische wereld, 1598-1648, Bruselas, 1971, vol. 2, pp. 1-71.

57 Se ha cuantificado para el caso de Cádiz, un número superior de 1000 individuos entre 1650 y 1778 . CRESPO Solana: op. cit. (nota 5), pp. 103-128.

58 Archivo Diocesano de Cádiz (ADC), 1029. Documentos de la mayordomía y patronato de la Nación flamenca. Existen otros documentos de la nación en el Archivo General de la Administración, Alcalá de Henares (AGA), Sección gobernación, Caja 6086: "Informe sobre antecedentes y características del hospital de San Andrés de los Flamencos", Madrid, 1802.

$59 \mathrm{AHN}, \mathrm{E}, 641$, expediente 716: memorial del 17 de noviembre de 1727 sobre los privilegios de la nación flamenca de Cádiz.

60 Bustos Rodríguez, Manuel: «Comercio y comerciantes en la Andalucía del Antiguo Régimen: estado de la cuestión y perspectivas», Obradoiro de Historia Moderna, 17 (2008), pp. 43-76.
} 
falta de desarrollo económico real aunque sabemos que fueron precisamente estas comunidades los auténticos sostenedores del comercio español-americano. El complejo contexto político internacional de finales del siglo XVII y el posterior problema de la guerra de Sucesión a la Corona de España, tras la ruina de la Casa de Austria, pareció sobredimensionar el problema extranjero. Pero lo que sí es cierto es que la década inmediatamente posterior a Utrecht significó el inicio de una era de renacimiento comercial para las redes internacionales de comercio. En un memorial sobre las consecuencias que el conflicto sucesorio trajo al comercio, su autor anónimo afirmaba que en 1698 el más importante comercio de Europa estaba en manos de los ingleses, de los holandeses y de los Spaniards (sic) y que de los tres, era precisamente la Monarquía la que más plata podía atraer hacia Europa (desde América) y más necesidad de manufacturas tenía al estar bastante incapacitada para sostener sus propias industrias $^{61}$. La nación flamenca española había desarrollado una larga trayectoria como intermediarios de los holandeses en la introducción de manufacturas textiles que el colosal sistema portuario neerlandés atraía hacía el puerto de Amsterdam y la estratégica isla de Texel (al norte de Frisia) a través de la navegación fluvial interior. Esto se complementaba aún más porque tras la guerra de Sucesión, las provincias meridionales se habían consolidado en un estado de periferia económica de la República Holandesa y los mercaderes flamencos que residían en territorios de la Monarquía hispana se vieron en la situación de utilizar el transporte y los servicios de las flotas holandesas si querían mantener sus negociaciones con los mercados del norte de Europa. Tal como afirmaba un cronista de la época, los holandeses se diferenciaban de los demás en que tenían unas "bien cimentadas alianzas" y "conocimientos de principios y menudencias del comercio" 62 , algo que los diferenciaba notablemente de los ingleses en su competencia por acceder a los mercados hispanos. Además, los británicos tenían, a diferencia de los holandeses y flamencos, más problemas de competencia y recelo político-religioso entre ingleses e irlandeses católicos por lo que las comunidades de esta nación en España tenían, al parecer, menos incidencia de cooperación entre ellos que en el caso neerlandés ${ }^{63}$.

Tras la guerra, las colonias extranjeras de Cádiz conocieron el inicio de un período de auge comercial caracterizado por la consolidación de la función de esta ciudad como centro de re-exportación y subsede financiera, actividades en la que los flamencos despuntaron durante varias décadas en la centuria precedente al haberse convertido en intermediarios especializados ${ }^{64}$. Por un lado tenían una funcionalidad logística

61 "The interests of the Several Princes and States of Europe considered with respect to the Succession of the Crown of Spain”, London, printed in the year 1698. Autor anónimo, p. 23. Impreso localizado en la British Library, Londres.

${ }^{62}$ Malo De Luque, Eduardo: Historia política de los establecimientos de Ultramar de las naciones Europeas, Madrid, 1788, por Antonio Sánchez, Librería de la Aduana Vieja, cap. II, p. 18.

63 Esta es en realidad una hipótesis digna de ser considerada y estudiada más ampliamente. No obstante se han descrito algunos indicios de estas relaciones entre ingleses protestantes e irlandeses católicos que no siempre fueron favorables a la hora de un entendimiento comercial. En el caso de Cádiz el problema fue básicamente religioso aunque no está del todo comprobado. Cf. García Fernández, Nélida: Comunidad extranjera y puerto privilegiado. Los británicos en Cádiz en el siglo XVIII, Universidad de Cádiz, 2005.

${ }^{64}$ Cf. Everaert, John: De internationale en Koloniale Handel der Vlaamse Firma's te Cádix, Brugges, 1973; Crespo Solana: op. cit. (nota 3), pp. 21 y ss. 
al trabajar como consignatarios de los buques que llegaban de diversos puertos del norte de Europa, tarea que se deriva del análisis de los contratos de fletamentos, sobre todo aquellos realizados en Amsterdam, en donde se incluía el periplo de escalas contenidas en un viaje comercial y la misión que tenían estos consignatarios. Cuando los buques holandeses llegaban a puerto era costumbre que los consignatarios subieran a bordo para recoger su propia mercancía e hicieran los trámites convenientes para ser admitidos a comercio. En estos hechos se daban situaciones habituales como que si el consignatario era un transeúnte holandés que no hablaba la lengua castellana, subía acompañado de un mercader flamenco de su confianza que hablaba en su nombre y, ello a veces se hacía con la intención quizás de despistar a los responsables de las aduanas ${ }^{65}$.

Pero además de ser los encargados de recibir las mercancías y depositarlas en los almacenes bajo su custodia, estos mercaderes también depositaban dinero ganado por las compras y ventas de productos en los viajes de comercio con América, utilizando dicho capital para invertir en las exportaciones a América. Es decir, y esto es algo en lo que se ha insistido menos, los comerciantes extranjeros financiaban el comercio con América, introducían barcos, embarcaban manufacturas y prestaban dinero para costear estos viajes, esperando, al regreso de las flotas, obtener beneficios en plata americana. Por ejemplo, en febrero de 1701 llegaron a Cádiz 900 paquetes de telas de Bretaña, vendidas por la firma Raphael Luberto y Abraham Isaak Da Roche de Amsterdam en Cádiz de parte del mercader de Amberes Jacques Lorenzo y depositadas en Cádiz en manos del consignatario Carlos Panhuys con objeto de ser embarcadas para América. La firma también había dado poder para firmar algunos contratos de bodemerijbrief (riesgos marítimos) en dicho viaje de comercio, tanto en la ida a Cádiz como en el viaje de negocios a América ${ }^{66}$. El dinero prestado para un contrato de riesgo servía para financiar este viaje, en conjunto con otros tantos contratos que llevase el navío. El precio concreto de estas mercancías ascendía a 4.496 ducados con 17 reales que se debían: "te betalen uit het thuis komen van de vloot uit Nova Spanje", es decir, cobrados a la vuelta del buque en la flota de Nueva España ${ }^{67}$. Es este caso, como en tantos otros, donde se ve esta cooperación dentro de la comunidad flamenca y de ellos con las casas de comercio de Amsterdam así como con otros mercaderes, participaban también intermediarios españoles, en muchos casos los propios funcionarios de la Casa de la Contratación o de las aduanas locales que solían trabajar también como empleados o socios de los mercaderes extranjeros. Si fuera posible analizar la cantidad de relaciones personales que los comerciantes de las distintas naciones tenían con los funcionarios, marinos, y negociantes autóctonos, quizás sería posible comprobar que estas microsociedades de naciones volcadas hacia sus propios fueros comunitarios eran un garante económico e incluso institucional para la marcha de los negocios locales. Hay un caso curioso en el trabajo que llevó a cabo Juan Domingo Saporito, comerciante de Cádiz, y también agente de la aduana durante

65 Hay algunas anécdotas de esta en los documentos de la oficina de la Sociedad del comercio de Levante. NA, Archivo del "Levantse Handel", 173. Correspondencia del cónsul holandés en Cádiz, 30 de enero de 1748.

66 Gemeente Archief Amsterdam (GAA), n.a. 5879, 837: poder del 11 de febrero de 1701.

67 GAA, n.a. 5879, 837: poder del 11 de febrero de 1701. "Transport". La mercancía eran "platillas", 4 cajas. 
unos años posteriores al suceso que se narra aquí. Saporito se encargaba de vender en su nombre los buques de la Sociedad del Comercio de Levante, algunos de los cuales fueron incluidos en las flotas americanas. En 1701 vendió el navío De Keyzer Henricus a Thomas Fell por 20.000 piezas de a ocho, vendidas la mitad al contado y la otra bajo una fórmula interesante, que estaba en realidad contratada y firmada por un negociante de Amsterdam: "zonde lopen op bodemerij tegen achtien procente" (corriendo un riesgo con un interés del 8\%). Está claro que este buque navegó a las Indias, aunque no se hace constar ${ }^{68}$. Este navío había sido anteriormente propiedad de Tomás Tellez, mercader de Sicilia y antes del holandés Isaak de Long quien en 1696 había sido propietario de una parte del navío, en una octava parte, como a veces era común entre los reders de Amsterdam ${ }^{69}$.

Es importante resaltar esta categoría analítica de intermediarios especializados que convertía a los miembros de la nación flamenca, muchos de los cuales, no se puede olvidar, eran holandeses católicos o no, y fueron algo así como oficinas sucursales para la importación. Contra todo lo que se ha dicho anteriormente en la debatida, y actualmente cuestionada, tesis del declive holandés, los datos marcoeconómicos señalan que a partir de principios del siglo XVIII la República Holandesa aún tenía un importante papel en las exportaciones del interior europeo, sobre todo procedentes del Báltico y de las zonas conectadas al hinterland del río Rhin ${ }^{70}$. Desde los primeros años del siglo XVIII, las Provincias Unidas defendió el convoy de la Sociedad de Levante en dirección a Cádiz para continuar con el avituallamiento de textiles cuyo destino final debía ser América, y con objeto, entre otras cosas, de compensar la fuerte rivalidad que en esta función hacían los mercaderes franceses ${ }^{71}$. Existen muchos datos sobre las manufacturas flamencas que salían hacia los mercados hispanos a través de los convoyes holandeses, como las toilles de Cambray, que en la primera década del siglo XVIII venían desde Amsterdam según afirmaba un mercader asentado en Cádiz: Gaspar de Coninq quien recibió de Jean-François varias remesas de estos productos por cuenta de su socio Robert de Franqueville, un manufacturero del interior ${ }^{72}$. Desde Amsterdam se importaba piel de camello, mercancía que llegaba a Cádiz, como fue el caso de unas pacas llegadas a bordo de un buque del comercio de Levante y entregada en mano de una firma de holandeses transeúntes que se domiciliaron temporalmente en la casa de la familia Van Kessel, una importante casa de negocios de la nación flamenca $^{73}$. La firma estaba compuesta por Rodrigo Emants y Jan Optenvoort, quienes llegaron a la ciudad en esos mismos buques con objeto de vender los productos ${ }^{74}$. La residencia temporal de los mercaderes viajeros en el hogar de una destacada familia de flamencos era algo habitual y casi una costumbre consensuada. La acogida de

68 GAA n.a. 4192, 579: 11 de febrero de 1701.

69 GAA, n.a. 6561, 1277: 10 de junio de 1701.

70 VRIES, Jan de: «Dutch Economic growth in comparative-historical perspective, 1500-2000», De Economist, 148 , n. 4 (2000), pp. 443-467, p. 452.

71 Sobre todo en el comercio directo con las colonias españolas de América.

72 GAA. n.a. 2941, 577: carta de 27 de mayo de 1701.

73 La dinastía Van Kessel, Coghen y Montefrío era una de las familias flamencas con más peso dentro de la nación. El testamento de Adriana Van Kessel, su matriarca, se encuentra en Archivo Histórico Provincial de Cádiz (AHPC), p.n. 23/5333, y es de 1740 .

${ }^{74}$ GAA n.a. $5879,837$. 
paisanos transeúntes se hacía, a veces, en muchas casas de posadas que algunos flamencos tenían como el caso del comerciante de vinos de Gante, Mathias Brugmann, quien abrió una posada para este fin con la dote de su esposa, María Ana Warens ${ }^{75}$. Pero era también común la acogida temporal en el Hospital de San Andrés, en la calle del Rosario de Cádiz o en las propias viviendas de las familias más adineradas que, eventualmente, tenían espacios acomodados para recibir a estudiantes de comercio, aprendices, viajeros y socios en general ${ }^{76}$. Era también habitual que algunos jóvenes mercaderes asistiesen en las casas de comercio más poderosas aun siendo nacidos ya en el seno de la nación, pudiendo así también adquirir bienes para mantener a la familia o a una madre viuda ${ }^{77}$.

En general, podía decirse que la relación entre holandeses y flamencos era estrecha incluso con aquellos mercaderes procedentes de las Provincias Unidas que no se integraban como miembros de la nación flamenca y preferían mantenerse adscritos al consulado de la ciudad, el cual constituía una minoría que tenía muchos problemas para resistirse a los impuestos y prebendas que la corona les intentaba imponer. Es interesante señalar aquí también que una buena parte de los problemas de los miembros del consulado holandés se solucionaron gracias a la colaboración de los amigos flamencos a juzgar por las informaciones de la correspondencia de los cónsules con la oficina de la Sociedad del Comercio de Levante en Amsterdam. Pero esto tenía lugar más que nada en relación a asuntos internos de la colonia sobre asuntos de negocios mientras que las cuestiones de impuestos reglados entre la Sociedad de Levante y la Corona española era arbitrado por representantes que elegían los propios mercaderes dentro de su consulado, como cuando en noviembre de 1765 se aprobó el impuesto del Natie Penningen que debían pagar los holandeses a la corona. Los mercaderes holandeses adscritos al consulado debían pagar un impuesto a la Corona española en calidad de consignatarios de buques holandeses y se requería que los negocios comerciales del puerto debían ser constatados mediante un acta notarial y ser custodiados estos papeles en casa del cónsul bajo la supervisión de dos diputados ${ }^{78}$. Este hecho destapa hechos curiosos en lo relativo a la colaboración de holandeses y flamencos en el puerto: una buena parte de estos impuestos no se pagaban ya que muchos de los consignatarios de los buques holandeses eran flamencos. Flamencos que se hacían pasar por holandeses u holandeses que se hacían pasar por flamencos para evitar así el pago de impuestos tanto a la Corona española como al propio cónsul holandés que debía rendir cuentas a la Sociedad del Comercio de Levante. Ello provocó más de una situación divertida como cuando ni la nación flamenca ni el consulado querían salir en acusación o defensa de "un brabanzón o flamenco Jan Baptista de Roo", quien actuaba como consignatario de buques de la Sociedad en 1767, y que como otros tantos

75 AHPC, p.n. 5/989, fols. 45-48v., Cádiz, 23 de marzo de 1712.

76 Por ejemplo, lo hicieron algunos mercaderes de la nación flamenca como: Livino Bernardo van den Broeck, la familia Coghen y Montefrío, etc.

77 Es el caso de Antonia de Anis, mantenida por su hijo que residía y trabajaba en la casa de comercio de Adriana Van Kessel (aparece también como Banquessel en este documento): AHMC, Padrón de 1713, n. 1003.

78 NA, Archivo Levantse Handel 173, Carta de Wilem Nagel a los directores de la Sociedad del comercio de Levante, Cádiz, 30 de septiembre de 1766. Hay documentos sobre Jan Baptista Roo en AHPC, p.n. 16/3765, fols. 140-142v. Es un poder para testar recíproco cuando su esposa se encontraba encinta, y fechado en julio de 1716. 
no afrontaban las normas ni de la Corona ni del Almirantazgo de Amsterdam. Jan Baptista de Roo era un negociante originario de Amsterdam pero vino a Cádiz como socio de una familia de flamencos, los Hercq y Vandentrille de Amberes y, casado con una española, Juana Grosso y Gómez, fue también mayordomo de la nación flamenca en $1738^{79}$. Y es que en relación al pago de impuestos, los mercaderes extranjeros tenían sus apaños de forma conectada con la forma en la que habían conducido su inserción social en otras familias españolas o de otros extranjeros. Muchas firmas de Flandes y Amsterdam, sobre todo de ésta última, se hicieron con el control directo de los beneficios de las rentas y aduanas de la Monarquía hispánica. Esto era relevante en el caso de las ciudades andaluzas, cuyas rentas llegaron a parar a mano de muchos judíos de la capital holandesa. Por ejemplo, en marzo de 1700 Gerard Martens se beneficiaba de la renta de la Alhóndiga de Málaga debido a que era el apoderado y a su vez único heredero por el fallecimiento de un miembro colateral de su familia, nacido en España y que fue comerciante de Málaga y el cual había recibido años antes dicho beneficio de manos del rey a cambio de una confiscación forzada de buques para la guerra $^{80}$.

Aunque la relación entre flamencos y holandeses no era preferentemente económica, puede decirse que ésta prevalecía en relación a un consenso de confianza y supervivencia dentro de toda la comunidad de lengua y cultura neerlandesa que estaban, además, emparentados en sus regiones de origen tras décadas de diáspora cruzada tanto dentro de los Países Bajos como por los reinos de la Monarquía hispánica. En estas relaciones se hacía notar especialmente una especie de confraternidad lingüística, ya que los flamencos servían muchas veces como intermediarios cuando los responsables de la aduana o los funcionarios de la Contratación usurpaban el papel del cónsul holandés y subían a los barcos para comprobar mercancías y pasajeros. Así, a niveles prácticos esta alianza se basaba en la connivencia de los flamencos que actuaban como consignatarios a la hora de la arribada de los convoyes holandeses a la bahía de Cádiz. En algunas ocasiones eran estos consignatarios flamencos los que de alguna manera encubrían las faltas de sus correligionarios del norte debido a que eran los transportistas de las importaciones flamencas pero también eran cómplices en las sacas ilegales de plata. En 1763 se dio un caso curioso sobre esta colaboración para el fraude. En abril de dicho año se confiscó por parte de las autoridades españolas una suma de 14.780 pesos fuertes (12 sacos sin declarar) del navío anclado en el puerto de Cádiz, De Vriendschap al mando del capitán Thomas $\mathrm{Poo}^{81}$. El gobernador de Cádiz aseguró que los funcionarios de las rentas reales habían actuado de acuerdo a lo estipulado en los tratados, en su obligación de sondear el navío, revisar la carga y descargar las mercancías dudosas en presencia de los consignatarios. Aunque el navío estaba consignado al cónsul holandés, Willem Nagel, fue una firma flamenca, la casa "Roo, Hercq y Vandentrille", quiénes declararon que había convenios y dis-

79 NA. Archivo Levantse Handel, 173: carta del 22 de diciembre de 1767.

80 NA, Archivo Nederlandse Gezanten en Consuls, 26: carta de particulares.

81 NA, Archivo Levantse Handel, 173: traducción al neerlandés de una respuesta del marqués de Grimaldi al enviado extraordinario y ministro plenipotenciario de los Estados Generales en la corte de España, Sr. Grave van Rechterem. 13 de abril de 1763. 
posiciones que permitían excepciones a las extracciones ilegales de plata. Se trataba de un convenio de vreemde Bodems (algo así como cubierta de extranjeros amigos) que permitía la extracción de oro y plata del reino sin permiso del rey siempre que se demostrase que era dinero obtenido de las ventas de mercancías propiedad de firmas reconocidas en la ciudad y que tenían obligación de enviar ese dinero a sus socios de otras ciudades. En la declaración se dijo que los sacos de dinero habían sido conducidos al barco por diferentes personas encargados por los flamencos "Roo, Hercq y Vandentrille" así como socios de otros miembros de la comunidad ${ }^{82}$. Este caso es conocido por el hecho quizás de que los mercaderes perdieron el juicio. Las leyes españolas decidieron que siempre se debían de pagar los derechos de salida en las exportaciones de plata, cosa que no hicieron y para ello se referían al artículo 25 del tratado de 1667 que confirmaba el derecho al pago de impuestos en los puertos de salida, defendiendo siempre el derecho real a recibir el beneficio. Los no cumplidores cumplieron penas, aunque los mercaderes flamencos recibieron un castigo menor (confiscación de la mercancía) en comparación al que recibió el capitán Poo (fue enviado a un presidio en África). El caso fue defendido por el cónsul Willem Nagel apelando a la sentencia a favor del capitán Poo y citaba casos pasados pero eran apelaciones que, en última instancia podían servir para proteger al navío, al resto de la carga que sí había sido declarada y a los intereses de sus dueños ${ }^{83}$. En estos casos se culpaba sólo al capitán quien tenía mucho que perder si era sorprendido pues rara vez se podía demostrar que el comerciante era cómplice o culpable.

\section{CONCLUSIÓN}

Las visiones locales sirven como observatorio de comportamientos que podríamos calificar como transnacionales. La información documental ofrece mucha información sobre dos aspectos principales que se deben esclarecer del comportamiento de las colonias de mercaderes extranjeros: por una parte, más que la agrupación en torno a los consulados de comercio, los comerciantes integraban auténticas microsociedades, comunidades corporativas que servían no solo para las defensas de sus intereses sino para desarrollar diferentes mecanismos de integración que iban más allá del marco familiar. Estos mecanismos, a veces de competencia pero también de cooperación o incluso de altruismo social, se basaban en una confraternidad corporativa orientada al bien común, la defensa de los privilegios y la salvaguarda de un fuero que los convertía en ciudadanos de primera en una sociedad tan hostil como fue la Europa del antiguo régimen en general. Pero sobre todo estos mecanismos ayudaban a que estos mercaderes fuesen los auténticos intermediarios especializados en los intercambios comerciales con todo lo que eso implicaba a nivel económico. Estos agentes, aparte

\footnotetext{
82 Ibidem. Ese derecho, según los flamencos, estaba estipulado por los tratados de comercio entre Holanda y España, de 1667 (hacía referencia explícita al artículo X de dicho tratado). Además estaba confirmado como privilegio a las naciones en el tratado de 1734 (artículos X y XI).

83 NA, Archivo Levantse Handel: copia de cartas del cónsul Willeem Nage al secretario L. Ernst, Madrid, 19 de julio de 1776 sobre la sentencia del fiscal contra el capitán Thomas Poo.
} 
de integrarse social y económicamente en Cádiz, gracias a sus vínculos familiares, desarrollaron unos mecanismos que explican tanto el considerable alcance de su red como el impacto de sus actividades económicas en un espacio socio-geográfico que se ampliaba más allá de las fronteras. La relación entre flamencos y holandeses no fue siempre la de unos socios bien avenidos, al igual que no lo fueron las existentes entre otras naciones y comunidades. En el caso neerlandés, como en otros tantos, también se vieron afectadas por los vaivenes de las rivalidades políticas y económicas, pero siempre aparece la lucha de la comunidad por subsistir, algo que se ve claramente en el análisis de las actividades mercantiles a un nivel microeconómico. Queda por comprobar la efectividad de estas redes más allá de los escenarios locales donde estas corporaciones se fortalecieron gracias al mantenimiento de su comercio global. Quizás la visualización de estas complejas redes sirva para demostrar que en el estudio de las comunidades mercantiles transnacionales el todo no es la simple suma de unas partes. 